BLS 32, No 1 2006. DOI: http://dx.doi.org/10.3765/bls.v32i1.3446 (published by the Berkeley Linguistics Society and the Linguistic Society of America)

\title{
Argument Structure and Adjuncts: Perspectives from New Guinea
}

\author{
MARK DONOHUE \\ Centre for Research on Language Change, Australian National University
}

\section{Background}

It is widely assumed that arguments and adjuncts differ in that arguments are licensed by a predicate, while adjuncts are not. The nature and number of arguments is thus strictly delimited in a clause, while adjuncts are essentially unbounded. (1) and (2) demonstrate the restrictions placed on possible arguments by the predicate in English; in (1) the verb only allows for a subject, while in (2) the verb requires both a subject and a single object. (3) shows the lack of any such restrictions on adjuncts.

(1) She slept $(*$ the cat $)(*$ the hot water).

(2) She admired *(the cat) $(*$ the hot water).

(3) She washed the cat (with the hot water) (in the laundry room) (for her sister) (with her daughter) (yesterday).

We can effectively describe the allowed participants in clauses in English (and many other languages) as shown in (4) (terminology from Bresnan 2001).

(4) Required: one SUBJECT

(Lexically) specified by verb: one (or more) OBJECT(s), one OBLIQUE

Unlimited, but not required: temporal reference, co-agent, beneficiary, instrument, location, source or goal (ADJUNCT(s))

A pattern is found in some languages of North-Central New Guinea in which there are restrictions on the number of participants in a clause. This can informally be stated as in (5).

(5) $\quad$ Required: one subject ( \pm pro-drop)

(Lexically) specified by verb: one object

Optional: time reference

Maximally one (per verb): co-agent, beneficiary, instrument, location, source or goal 
This means that: (i) trivalent clauses are not licensed by single verbs; (ii) maximally one oblique or adjunct may be present for any one verb (and there is little, if any, difference between these two types of participants); (iii) an analysis in terms of positions in the clause, or case-marking differentiation, or even pragmatic positions, is not adequate to describe the data; (iv) we must simply specify firstly a restriction on the number of adjuncts in the clause, and secondly (and less strongly, for Skou) a conflation of the distinction between oblique and adjunct.

In the next section I shall present some brief background notes on the two languages, followed by data from One and Skou, in that order, presented separately. Following the data I shall discuss the implications of the data for considerations of argument structure.

\section{Background on the Languages: Skou and One}

The two languages discussed here are spoken in North-Central New Guinea. Skou is a coastal language spoken immediately west of the Indonesia-Papua New Guinea border, while One is spoken inland to the east in Papua New Guinea.

One is a Torricelli language of the West Wapei group, spoken in various villages from the eastern Bewani mountains. The variety described here is Molmo One, spoken in the Pibi river valley by approximately 500 people (Laycock 1975, Crowther 2001, Sikale et al. 2002).

Skou is the westernmost language of the Macro-Skou family, spoken by about 700 people in three villages (Laycock 1975b; Donohue 2002, 2006, 2008). There are a number of broad similarities shared by the two languages: (1) verbs inflect for subject by monoconsonantal prefix, a feature of the area (prefixes are phonologically restricted to a defined set of verbs); (2) there is little case marking, only instruments being overt; (3) only valency-affecting processes are weak applicatives (restricted lexically); and (4) there are restrictions on the number of participants in a clause (both arguments and adjuncts). Despite the similarities, there are a number of striking differences between Skou and One: (1) Skou is SOV, while One is SVO; (2) Skou is tonal and (predominantly) monosyllabic, while One has weakly contrastive stress (verbs only) and is predominantly disyllabic; (3) Skou has a switch reference system, while One has a topic-driven coordination system; and (4) Skou makes extensive use of $\mathrm{N}+\mathrm{V}$ complex predicates and has configurational NPs. The fact that, despite these differences, the two languages show such striking similarities in terms of their treatment of obliques/adjuncts suggests that the pattern described here pertains to a greater number of languages in the area as well, though documentation is so far lacking.

\section{One}

The order of elements in the One clause is summarized in (6) (ignoring hierarchical structure in the clause). (7) and (8) show maximally 'full' clauses, demonstrating the relative positions described in (6). Raising tests and verbal prefixation uniquely identify subjects, and the ability to be cross-referenced on the verb as a suffix if $1 \mathrm{SG}$ uniquely identifies objects. 
(6) Time Subject (Adverb) Verb (Auxiliary) Object Oblique/Adjunct

(7) Time Subj $V$ Obj Adjunct

Nounke i em au nula=ne.

yesterday $1 \mathrm{SG}$ get sago tong=INSTR

'I got the sago with tongs yesterday.'

Subj Adv V Oblique
Wo puli flane pari ninkleli.
3SG wife quickly go.up garden
'His wife went to the garden.'

Only instruments are overtly case-marked, which have more positional variation than other adjuncts, being able to both follow (commonly) or precede (rarely) an object. (9) shows the relative freedom of position found with an instrument, and (10) demonstrates that locations are more restricted. The same is true for goals and sources.

a. Wo tere aila $\mathrm{eko}=$ ne.

3SG cut wood ax=INSTR

'He cut the wood with an ax.'

b. Wo tere eko ne aila.
a. Wo tere aila ninkleli.
3SG cut wood garden
'He cut the wood in the garden.'
b. * Wo tere ninkleli aila.

Despite the positional freedom that instruments display, they cannot co-occur with a location or goal in the same clause, regardless of the relative order of the two adjuncts (or obliques), or whether the instrument precedes or follows a nominal object.

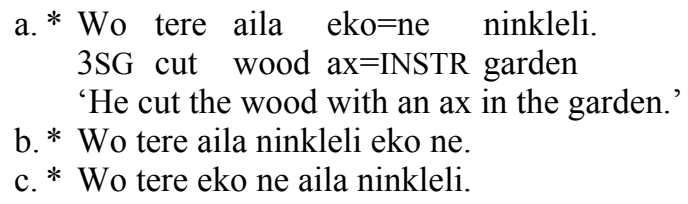

Similarly, though perhaps less surprisingly by virtue of their fixed and identical positions, goals or sources and locations cannot co-occur in the same clause, regardless of their relative ordering. (12) shows goal + location combinations, and (13) shows source + location combinations.
a. Wo pari Laurela.
3SG go.up Laurela
'He went up to Laurela.' 


\section{Mark Donohue}

b. Wo pari pleni po'u.

3SG go.up path steep

'He went up on a mountain path.'

c. * Wo pari Laurela pleni po'u.

d. * Wo pari pleni po'u Laurela.
a. I te Wisoli.
1SG come.around Wisoli
'I come from Wisoli.'
b. I te pleni po'u.
1SG come.around path steep
'I came on a mountain path.'
c. * I te Wisoli pleni po'u.
d. * I te pleni po'u Wisoli.

Coding a traveled-through location as an instrument, a grammatical option in One, does not save the grammaticality of sentences such as (14b) or (14c).

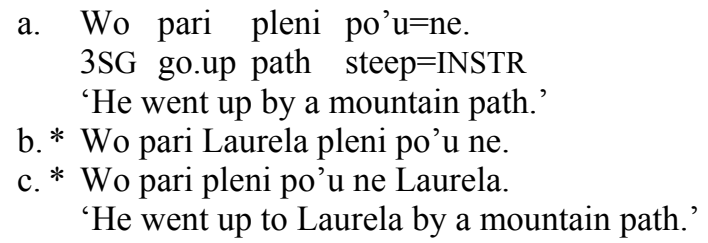

Clauses with beneficiary or recipient arguments show an obligatory reduction in surface participants to satisfy the strict restrictions on number of arguments in a clause. This accommodation can follow either of two strategies. In the first we see a form of 'dative lowering', in which the recipient or beneficiary is realized as the possessor of the object in the clause, as in (15) and (18). Alternatively, the three arguments can be shared between two verbs in a serial verb construction (SVC). In (16) yani subcategorizes for an agent and a theme, and the recipient is introduced as the oblique argument of $y i$ 'go', while in (17) it subcategorizes for an agent (shared with yupu) and a recipient, and yupu introduces the theme as its object. In both cases each verb in the SVC subcategorizes for only two arguments. With beneficiary constructions yupu is not grammatical, as seen in (20).

$$
\begin{aligned}
& \text { Wo y-ani [NP i puli malma toma ]. } \\
& \text { 3SG 2/3SG-give 1SG wife devil stone } \\
& \text { 'He gave my wife('s) money.' }
\end{aligned}
$$

(16) Wo y-ani malma toma $y-i$ i puli. 3SG 2/3SG-give devil stone 2/3SG-go 1SG wife 'He gave money to my wife.'

$$
\begin{aligned}
& \text { Wo y-upu malma toma y-ani i puli. } \\
& \text { 3SG 2/3SG-get.and.transact devil stone 2/3SG-give 1SG wife } \\
& \text { 'He gave money to my wife.' }
\end{aligned}
$$


(18) Wo y-aro-le [NP apuwa tapi ama=enu ].

3SG 2/3SG-peel-ITER taro skin mother $=$ GEN

'She's peeling the taro for mum.' (= 'She's peeling mum's taro.')

(19) Wo y-aro-le apuwa tapi y-ani ama.

3SG 2/3SG-peel-ITER taro skin 2/3SG-give mother

'She's peeling the taro for mum.'
* Wo y-upu
apuwa tapi y-aro-le
y-ani
ama.
3SG 2/3SG-get.and.transact taro skin 2/3SG-peel-ITER 2/3SG-give mother
'She's peeling the taro for mum.'

The serialization strategy is frequently used to allow an adjunct to appear in an otherwise 'saturated' clause, providing rescue options for translations of clauses such as (11). In (21) we can see the use of yem 'get' serialized with tere to introduce an instrument, and in (22) wae e 'be at' introduces the source of the motion in an inherently temporally-sequenced serial verb construction.

(21) Wo y-em eko tere aila ninkleli.

3SG 2/3SG-get ax cut wood garden

'He cut the wood with an ax in the garden.' (monoclausal)
Meli n-ae n-e moren panteri Laurela.
children 3PL-sit 3PL-be house.LOC 3PL:ascend Laurela
'The children are going up to Laurela from the house.'

Co-agents ('accompaniers') are coded in relative clauses formed with the verb ane 'and'.

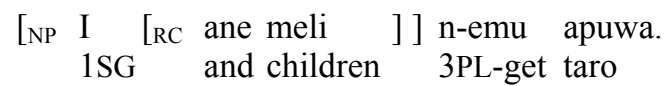

'The children and I got the taro.'

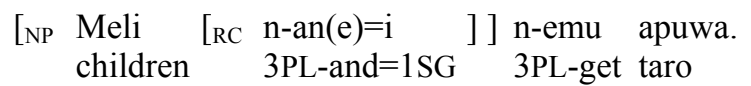

'The children and I got the taro.'

When the discourse is such that there is no appropriate second verb to use to introduce a new participant, the main verb will be repeated in order to allow two oblique arguments, each licensed by a separate instance of the main predicate. In (25) we can see that the first instance of palo (itself appearing in the serial verb construction fanta palo) appears with a source oblique tiroa 'from the rinser', and in the second use the adjunct mairop is a goal, as well as being the object of nal.

(25) (Making sago:) [When you rinse sago, the scrapings stop at the strainer ...]

ani sa ese fanta palo tiroa palo nal mairop.

sago.meat TOP FUT fall go.down rinser go.down fill catcher

'.... and the sago meat goes down from the rinser to the catcher.' 
Even in clauses that could license all the participants that are called for, a subject, object, and oblique/adjunct, we can observe a preference for the use of less argument-dense strategies (see DuBois 1987, DuBois et al. 2003, and Bickel 2003 for similar discussion on the limits to the number of NPs in clauses). In (26), taken from a dictionary definition of a deadfall trap, the proposition could have been expressed with a single clause, as in (27). Instead, the author chose to split the clause into two, with smaller NPs and a more 'diffuse', low-density information packaging strategy.

(26) (Making a deadfall trap): (He) cuts some rattan and forms a loop with it, slipping the loop around and fastening it to the tree. Then ...]

mala y-ona apa sa wala y-eri

child(=small part of tree) 2/3SG-hang.TR rattan TOP side 2/3SG-come.up

y-apa $\quad \mathrm{y}$-e tiri $\ldots$

2/3SG-hang.INTR 2/3SG-be above

'... (he) hangs up the small side of the tree by the rattan and hangs it above [so that later when an animal goes past it will fall down on top of the animal and kill it].'

$$
\begin{array}{lll}
\text { Subj } & \text { Obj } & \text { Adjunct }_{\text {location }} \\
\text { (Wo) y-ona } & \text { (aila) wala mala apa tiri. } \\
\text { 3SG 2/3SG-hang.TR tree side child rattan above } \\
\text { '(He) hangs the small side of the tree on the rattan above.' }
\end{array}
$$

Some verbs subcategories for a subject and an oblique, not a subject and an object; we have already seen verbs of motion that satisfy this subcategorization frame in (8), (12)-(14), and (16), but there are other predicates not involving motion with such 'quirky' patterns. The oblique is not case-marked in any manner different to that seen with 'normal' objects, nor is there any necessary difference in the verbal morphology employed. The obliques of these verbs are distinguishable from objects by their inability to appear with adjuncts in simple clauses, since the restriction on only one NP filling the role of oblique or adjunct per clause applies to them as well as motion verbs ((12)-(14)). Clauses headed by verbs with obliques rely heavily on serialization to achieve the expressivity of the more common subject-object clauses. In (28), the (complex) predicate por ye subcategorizes for a subject, wo, and an oblique, mala (compare with (12a)). An adjunct such as ninkleli may not be directly added to the clause, but may be mentioned in a relative clause, as shown in (29) (compare with (21) and (22)).

(28) a. Wo por y-e mala.

3SG laugh 2/3SG-be child

'He laughed at the child.'

b. * Wo por ye mala ninkleli.

$$
\begin{aligned}
& \text { Wo por y-e [NP mala }[\mathrm{RC} \text { w-ae ninkleli }]] \text {. } \\
& \text { 3SG laugh 2/3SG-be child 2/3SG-sit garden } \\
& \text { 'He laughed at the child (who was) in the garden.' }
\end{aligned}
$$


The data we have seen so far shows that only one oblique is allowed per clause, and only one adjunct is allowed per clause; either an oblique or an adjunct may appear in a clause, but not both; and any clause that might be expected to be trivalent uses strategies to avoid a third argument. It could be argued that all of these restrictions simply reflect a really tight set of phrase structure conditions that allow for no doubling, and only one adjoined position. The non-cooccurrence of instruments and locations suggests that the factors involved are more complex than this - see the examples in (11), showing that an instrument, which shows relative freedom of position ((6)), cannot occur with a fixed-position location. Examining clauses with topical elements presents the evidence that a simple template is not enough to model the restrictions in the language.

Topicalization, optionally marked with $s a$, is another coding option for any participant in the clause (only in the event of the topic being an instrument is there any evidence of this being a dynamic process, the evidence being the optional postposition-stranding that is found with the instrumental clitic ne).
a. Wo (sa), _ tere aila eko=ne.
3SG TOP cut wood ax=INSTR
'HIM, (he) cut the wood with an ax.'
wood TOP 3 SG cut $-a x=I N S T R$
'THE WOOD, he cut (it) with an ax.'
b. Aila (sa), wo tere _ eko=ne. ax TOP 3SG cut wood (INSTR)
'AN AX, he cut the wood with (it).'
c. Eko (sa), wo tere aila _ (ne).
d. Ninkleli (sa), wo tere aila garden TOP 3SG cut wood
'(IN) THE GARDEN, he cut the wood (there).'

It might be thought that if an adjunct (or oblique) is coded in the preclausal topic position, the postverbal position would be 'freed' for another adjunct; this is not the case. One adjunct in the topic position does not license the appearance of a separate adjunct or oblique in situ, as can be seen in (31)-(33).

$$
\begin{aligned}
& \text { a. * Eko (sa), wo tere aila - (ne) ninkleli. } \\
& \text { ax TOP 3SG cut wood (INSTR) garden } \\
& \text { 'AN AX, he cut the wood with (it) in the garden.' } \\
& \text { b. * Ninkleli (sa), wo tere aila eko=ne } \\
& \text { garden TOP 3SG cut wood ax=INSTR } \\
& \text { '(IN) THE GARDEN, he cut the wood (there).' }
\end{aligned}
$$
b. * Ninkleli (sa), wo tere aila eko=ne garden TOP $3 \mathrm{SG}$ cut wood ax=INSTR

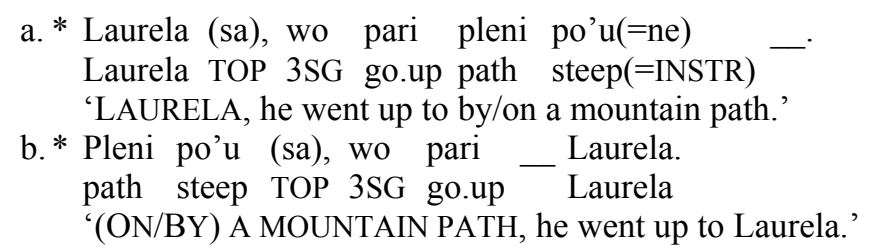


The fact that, even when topicalized with no overt 'filler' in the post-object position, this position is not available to host another adjunct suggests that, rather than being phrase structure-dependent, there is simply a stipulation on the number of participants in a clause, including adjuncts as much as arguments. Adjuncts are not 'additional' to the clause, as is normally assumed, but can 'interfere' with the realization of arguments (and/or vice versa) just as much as other arguments can.

In the next section, I examine data from Skou, an unrelated language from the same broad geographic area in North-Central New Guinea. In Skou we can see similar restrictions on the appearance of adjuncts, though not quite as strict as in One, and similar evidence for the integration of arguments and adjuncts together in the clause.

\section{Skou}

We find a more complex phrase structure in Skou than One, with two positions for non-terms, testable by their position with respect to the auxiliary. The postauxiliary position is used by locations, while the pre-auxiliary position hosts any other obliques or adjuncts. As with One, an (overtly marked) instrument shows positional variation, optionally appearing before the object (or following it). The difference between the two non-term positions is illustrated in (35) and (36).

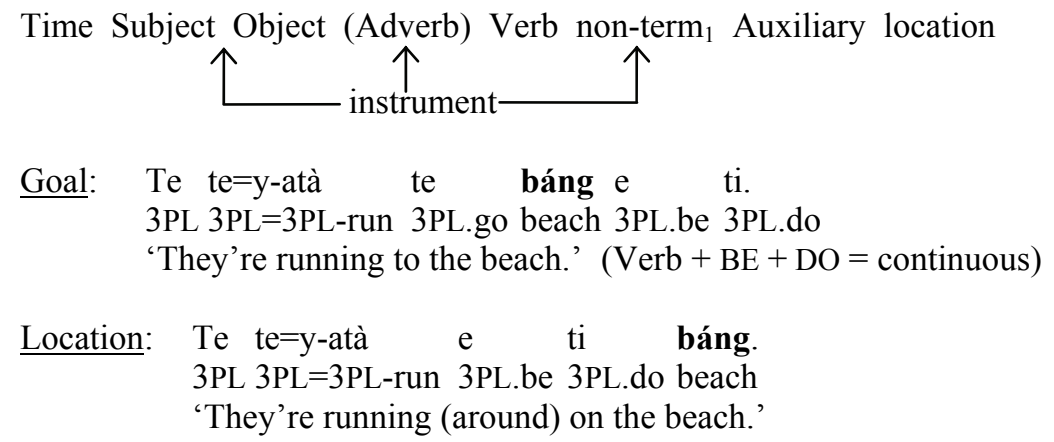

Many of the facts relevant to argument structure restrictions in Skou are identical to those in One, despite the many typological differences. As with One, instruments are less constrained than other adjuncts, and are overtly marked. In Skou an instrument may appear before an object, before the verb, or in the non-term 1 position.
a. Ke rangwaue=pa rí ke=lé.
3SG.NF ax=INSTR tree 3SG.NF=fell
'He felled the tree with an ax.'
b. Ke rí rangwaue pa ke=lé.
c. Ke rí ke=lé rangwaue pa. 
The same restriction on co-occurrence of two non-terms in one clause that was seen in One also applies in Skou, with a minor relaxation: a preverbal (and overtly case-marked) instrument may co-occur with a postverbal oblique goal. The instrument must be preverbal for this to be grammatical, as seen in (38b-c).

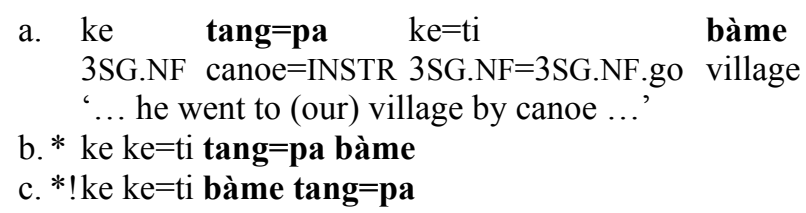

Clauses are markedly less acceptable with a preverbal instrumental adjunct and a postverbal participant other than a goal oblique, though this is more acceptable than having two postverbal adjuncts.

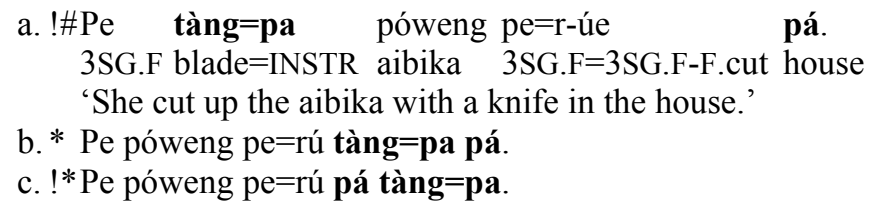

Even in Skou, in which there are two clearly separate postverbal positions (see (35) and (36)), they cannot be simultaneously filled by two different adjuncts. Even though rangwaue $=p a$ and lihi clearly occupy separate structural positions (compare with (35) and (36)), the two adjuncts may not co-occur.

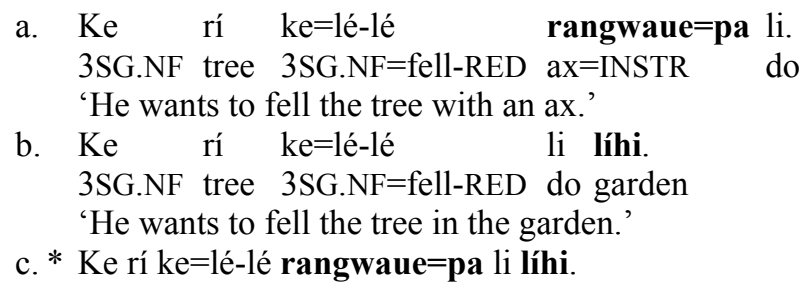

Repair strategies allowing the coding of both an instrument and a location involve the use of serial verb constructions, or simply two clauses chained together (this difference is overtly marked in Skou).

$$
\begin{aligned}
& \text { Rangwaue ke=ké }=\mathbf{k o} \quad \text { rí ke=lé (líhi). } \\
& \text { ax 3SG.NF=get }=\text { OBV tree 3SG.NF=fell garden } \\
& \text { 'He got an ax and felled the tree (in the garden).' }
\end{aligned}
$$

Just as in One, the predicate 'give' requires two verbs in an SVC, one to specify the theme and one to introduce the recipient. It is grammatical to code all three arguments in one clause, but it is considered 'better' discourse structure to have the object more distant from the postverbal material. (42) is an acceptable 


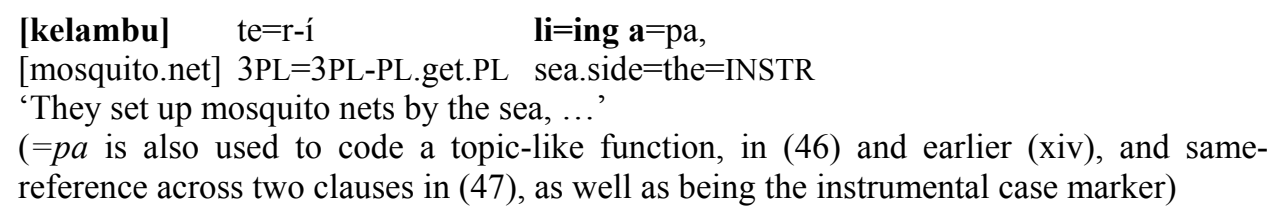

As with One, some predicates subcategories for $<\mathrm{SUBJ}$, OBL $>$. In these cases the OBL is coded following the verb, and cannot occur with an adjunct (compare the predicate in (48) with (44)).

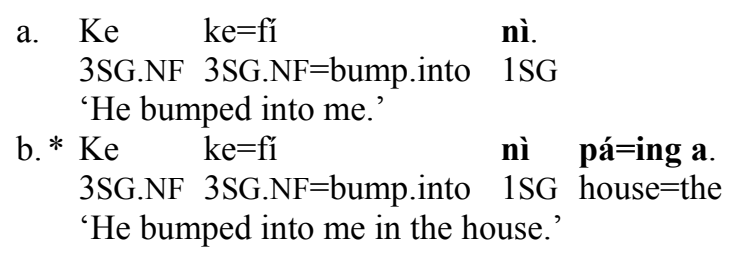

$$
\begin{aligned}
& \text { Ke } \mathrm{ke}=\mathrm{k}-\mathrm{e} \quad \text { ti } \quad \text { pá }=\text { ing } \mathbf{a}=\mathrm{pa} \quad \mathrm{ke}=\mathrm{fí} \quad \text { nì. } \\
& \text { 3SG.NF 3SG.NF=3SG.NF-go.up 3SG.NF.go house=the=INSTR 3SG.NF=bump.into 1SG } \\
& \text { 'He went into the house and bumped into me (there).' }
\end{aligned}
$$

\section{Enriching Theories of Argument Structure}

These data suggest that obliques, a subcategorized-for function, should be grouped with adjuncts, a non-subcategorized-for function (at least optionally). Rather than all the grammatical function labels of Bresnan (2001) being separate and distinct, we find the following distinctions can be motivated.

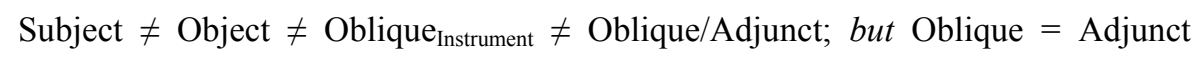

Adjuncts are not simply freely adjoined to a clause, the basic positions of which are determined in the argument structure of the predicate. The restriction is not simply a (phrase) structural restriction on positions. We must reevaluate the status and categories of adjuncts and arguments. Approaches such as Cinque (1999) present a model that is diametrically opposite to that suggested by these data; a multitude of functional projections would allow for multiple adjuncts. Are these functional projections more restricted in some languages than in others? This implies that functional projections are a parametrizable feature, and not a universal.

Simply declaring 'obliques' and 'adjuncts' to be separate GFs does not account for their mutual exclusion; the differential behavior of instruments in Skou is similarly left unexplained (though see Donohue and Donohue 2004). This implies that grammatical functions (or their structural equivalents in different frameworks) are as much a parametrizable feature as are more 'surface' phenomena such as case and agreement. Furthermore, it implies that grammatical functions other than arguments are subordinate to discourse-like constraints on argument realization (DuBois et al. 2003), and that an informed theory of argument 
Mark Donohue

structure must pay as much attention to these discoursal factors as it does to lexical factors.

\section{References}

Bickel, Balthasar. 2003. Referential Density in Discourse and Syntactic Typology. Language 79:708-736.

Bresnan, Joan. 2001. Lexical Functional Syntax. Oxford: Basil Blackwell.

Cinque, Guglielmo. 1999. Adverbs and Functional Heads: A Cross-Linguistic Perspective. Oxford University Press.

Crowther, Melissa. 2001. All the One Language(s): Comparing Linguistic and Ethnographic Definitions of Language in New Guinea. B.A. thesis, Department of Linguistics, University of Sydney.

Donohue, Cathryn, and Mark Donohue. 2004. On the Special Status of Instrumentals. In Miriam Butt and Tracy Holloway King, eds., Proceedings of the LFG '04 Conference, 209-225. Published online at http://cslipublications.stanford.edu/site/ONLN.html.

Donohue, Mark. 2000. One Phrase Structure. In Keith Allan and John Henderson, eds., Proceedings of ALS2k, the 2000 Conference of the Australian Linguistic Society. University of Melbourne. Published online at http://www.arts.monash.edu.au/ling/archive/als2000/proceedings.html.

Donohue, Mark. 2005. Configurationality in the Languages of New Guinea. Australian Journal of Linguistics 25:181-218.

Donohue, Mark. 2006. Negative Grammatical Functions in Skou. Language 82(2):383-398.

Donohue, Mark. 2008. Complex Predicates and Bipartite Stems in Skou. Studies in Language 32(2):279-335.

DuBois, John W. 1987. The Discourse Basis of Ergativity. Language 63:805-855.

DuBois, John W., Lorraine E. Kumpf, and William J. Ashby. 2003. Preferred Argument Structure: Grammar as Architecture for Function. Amsterdam: John Benjamins.

Sikale, John, Melissa Crowther, and Mark Donohue. 2002. Silla palla Molmo miri [Molmo One dictionary]. Sandaun Province Department of Education and The University of Sydney.

Mark Donohue

The Centre for Research on Language Change

Australian National University

Canberra, ACT 0200, Australia

mark@donohue.cc 